\title{
JUVENTUDE E ANTROPOLOGIA: UMA RELAÇÃO CONTROVERSA
}

\author{
JoÃo BATISTA DE MENEZES BITTENCOURT ${ }^{1}$ \\ AleXANDRE BARBOSA PEREIRA ${ }^{2}$
}

É no mínimo curioso o fato da juventude ser um fenômeno pouco estudado pela antropologia brasileira, uma vez que estamos falando de uma ciência que se propõe a refletir sobre os seres humanos em toda sua diversidade e complexidade. Quando atentamos para a história da antropologia produzida desde o norte, percebemos que, embora na maioria dos casos não se abordando especificamente a juventude como categoria social, a questão das fases da vida surge com um pouco mais de destaque, ainda que a partir da relação com outros fenômenos em uma mesma sociedade. Uma importante exceção é o clássico Coming of Age in Samoa (1949) de Margaret Mead, em que a antropóloga, efetivamente, direciona seu olhar para os processos formadores da condição infantil e juvenil entre os samoanos. Os demais trabalhos que se dedicaram a pensar a juventude não-ocidental se preocuparam de maneira mais incisiva com os ritos de passagem (FIRTH, 1998 [1936]; CLASTRES, 2003 [1974]; VAN GENNEP, 2011 [1977]). Sem sombras de dúvida, as discussões sobre esses ritos são extremamente importantes, uma vez que apontam para uma condição juvenil vivenciada como uma etapa liminar ${ }^{3}$ em que não se é mais criança e tampouco adulto. A grande contribuiç̧ão desses estudos para as futuras pesquisas sobre juventudes foi a desmistificação da ideia de que a transição para o mundo adulto se expressava no plano biológico (mudanças físicas e hormonais) indicando que essa passagem se configura como uma mudança de status social.

Possivelmente, uma explicação razoável para esse "suposto desinteresse" de antropólogos(as) está no fato de a ciência antropológica em sua origem ter dirigido suas lentes para povos que não possuíam em sua estrutura social e organizacional a expressão da

\footnotetext{
1 João Batista de Menezes Bittencourt é Doutor em Ciências Sociais e Professor do Instituto de Ciências Sociais da Universidade Federal de Alagoas, onde atua nos cursos de graduação em Ciências Sociais e nos Programas de Pós-Graduação em Sociologia e Antropologia Social. É líder do grupo de pesquisa Labjuve - Laboratório das Juventudes, membro-fundador da REAJ - Rede de estudos e pesquisas sobre ações e experiências juvenis e coordenador da Punk Scholars Network Brasil.

2 Alexandre Barbosa Pereira é Doutor em Antropologia Social e Professor do Departamento de Ciências Sociais da Universidade Federal de São Paulo, onde atua nos cursos de graduação em Ciências Sociais e no Programa de Pós-Graduação em Ciências Sociais. É membro-fundador da REAJ - Rede de estudos e pesquisas sobre ações e experiências juvenis.

${ }^{3}$ A ideia de liminaridade compreende uma situação transitória onde os indivíduos estão destituídos temporariamente de uma posição social. É uma espécie de entre-lugar indefinido que antecede os ritos de passagem (TURNER, 1974).
} 
juventude enquanto uma "fase da vida", ou seja, um momento específico para se vivenciar experiências juvenis como uma etapa que constitui o ciclo da vida. Desse modo, a categoria juventude era percebida por esses mesmos pesquisadores como um construto ocidental, logo não faria sentido se preocupar com algo que егa praticamente inexistente nas populações não-ocidentais. No entanto, ainda que sob outras perspectivas, como a do rito de passagem, a questão do ciclo da vida sempre foi um tema importante para essa chamada antropologia clássica que se preocupou com as sociedades dos "outros".

A antropologia tem passado por mudanças importantes ao longo do tempo. Estudos sobre as transformações sociais, os modos de vida e as dinâmicas relacionais próprias do ocidente já figuram entre as preocupações da disciplina desde a primeira metade do século XX. Mesmo assim, a antropologia, e particularmente a brasileira, continuou sem dar a devida atenção ao fenômeno da juventude, diferentemente de áreas como Educação, Psicologia e Sociologia, que possuem uma vasta e robusta produção. Uma de nossas hipóteses é a de que não se trata efetivamente de um desinteresse, mas sim de uma dificuldade em atentar para questões centrais das sociedades urbano-ocidentais do norte e do sul. Como afirma Bruno Latour (1994), a antropologia sempre foi muito ousada para falar de aspectos centrais das outras sociedades, mas muito pouco criativa para abordar questões centrais de sua própria. Daí a juventude ser um tema muito mais sociológico do que antropológico.

Para se ter uma dimensão do contraste na produção de pesquisa nas distintas áreas do conhecimento das ciências humanas, basta uma rápida consulta no catálogo de teses e dissertações da Capes com a palavra "Juventude", para verificar a desvantagem numérica da produção antropológica frente à sociológica. Averiguando o número de dissertações e teses produzidas nos programas de Antropologia e Sociologia entre 2000 e 2017 encontramos o seguinte resultado: Antropologia (33 mestrado e 20 Doutorado) = 53; Sociologia (91 mestrado e 45 doutorado) $=136$.

Contudo, nosso objetivo nessa apresentação não é tecer críticas à ciência antropológica produzida no Brasil em decorrência dessa ausência de trabalhos sobre o fenômeno das juventudes, e sim refletir sobre essa evidência empírica.

Podemos dizer que os estudos sobre juventude no Brasil são relativamente recentes. As primeiras publicações estão situadas na segunda metade do século $X X$, especificamente no final dos anos $1960^{4}$, e estas não tinham como foco a juventude, e sim questões como a educação, o conflito de gerações, a marginalidade, etc. Uma produção

\footnotetext{
${ }^{4}$ Não podemos deixar de mencionar o trabalho pioneiro da Antropóloga Ruth Cardoso, "O papel das associações juvenis na aculturação dos japoneses", de 1959, resultado de uma especialização na FFLCH-USP.
} 
bastante significativa dessa época foram os 4 volumes de Sociologia da Juventude (1968) organizado por Sulamita de Britto. A obra trazia traduções inéditas de textos que se propunham a discutir a condição juvenil, que naquele momento era vista quase exclusivamente sob as lentes funcionalista e marxista. Karl Marx, Karl Mannheim, Talcott Parsons, Margareth Mead, Georges Lapassade, Albert K. Cohen, Jurgen Habermas foram alguns nomes que figuraram nessas publicações, sem esquecer a contribuição dos estudiosos brasileiros Otávio lanni ${ }^{5}$ e Gláucio D. Soares.

A figura do estudante ao longo das décadas de 1960 e 1970 tornou-se uma referência para os(as) pesquisadores(as) que passaram a enxergar nesse ator social o reflexo de mudanças que vinham acontecendo em outros países. Nesse sentido, devemos reconhecer a importância do trabalho da socióloga Marialice Foracchi na consolidação dos estudos sobre juventude no país. Fortemente influenciada pelos escritos de Karl Mannheim, a estudiosa escreveu textos de enorme importância sobre o papel do estudante na sociedade brasileira, transformando, assim, a noção de juventude, efetivamente, em uma categoria analítica, com destaque para as obras "O estudante e a transformação da sociedade brasileira" (1965) e "A juventude na sociedade moderna"(1972). Com a instauração da ditadura militar, pesquisas que se propunham a analisar as ações do movimento estudantil foram proibidas ${ }^{6}$, desse modo, assistimos a um hiato ao longo de aproximadamente duas décadas.

O enfraquecimento da ditadura militar, a esperança de abertura política e o processo de "massificação" promovido pela indústria cultural trouxeram a juventude de volta para o cenário. As primeiras expressões das chamadas "culturas juvenis" começam a ganhar destaque nos meios de comunicação, passando a chamar a atenção dos(as) estudiosos(as) que viam aqueles grupos como "pequenas sociedades" que se organizavam mediante regras específicas. A discussão em torno da produção das identidades juvenis aproxima a antropologia dos estudos sobre juventude e surgem os primeiros trabalhos sobre punks, funkeiros e hip hopers. Merecem destaque nesse período a dissertação de mestrado "Movimento punk na cidade: a invasão dos bandos sub", da antropóloga Janice Caiafa, defendida no Programa de Pós-graduação em Antropologia Social da UFRJ no ano de 1985, que fora publicada como livro no mesmo ano e a tese de doutorado "O baile funk carioca: festas e estilos de vida metropolitanos", de Hermano Viana, defendida em 1987 no Programa de Pós-Graduação em Antropologia Social do Museu Nacional. Podemos dizer que esses

\footnotetext{
${ }^{5} \mathrm{O}$ texto "O jovem radical" que consta nessa coletânea foi publicado originalmente em 1963 no livro Industrialização e desenvolvimento social no Brasil.

${ }^{6}$ O poder jovem, trabalho do historiador Arthur José Poerner, publicado originalmente em 1968, foi um dos livros censurados pelo ato institucional n. 5 .
} 
trabalhos inauguraram um campo específico dos estudos sobre juventude no Brasil, destacando a sociabilidade e o lazer como elementos decisivos na produção das experiências desses agentes.

Nos anos 1990 assistimos a uma proliferação de dissertações e teses sobre os grupos juvenis de estilo (KEMP, 1993), que cada vez mais passam a ser vistos como protagonistas no processo de socialização das juventudes, com destaque para os trabalhos de Helena Wendel Abramo (1994), Márcia Regina da Costa (1993) e Glória Diógenes (1998). Nas décadas seguintes, as discussões sobre juventudes vieram acompanhadas de um conjunto de mudanças significativas na sociedade brasileira. O aumento do tempo de escolarização decorrente de políticas que estimularam a permanência do jovem na escola, a expansão das universidades públicas e institutos federais, o aumento de poder de compra das classes $C$ e D, a expansão comunicacional decorrente da popularização da internet e a reconfiguração da ação política através das chamadas "pautas identitárias" provocaram mudanças consideráveis nas experiências juvenis, o que, por sua vez, fez aumentar o interesse dos(as) estudiosos(as), reforçando ainda mais o caráter interdisciplinar das pesquisas.

Para estudar as juventudes no contexto contemporâneo é imprescindível estarmos atentos aos múltiplos agenciamentos que atravessam as cartografias dos agentes e como estas modificam a relação destes com espaços, contextos e situações. As teses geracional e classista que outrora deram o tom dos debates acadêmicos ${ }^{7}$ sobre o tema não conseguem mais captar a complexidade das experiências juvenis; a estas somam-se discussões sobre marcadores sociais da diferença e interseccionalidade. Os artigos aqui reunidos trazem justamente essa multiplicidade de agenciamentos que dão sentidos às experiências contemporâneas dos jovens brasileiros. Neles, encontraremos os jovens em diferentes posições e performatizando diversificados papéis. Assim, poderemos encontrar algumas das múltiplas formas de ser jovem na contemporaneidade, como estudante, universitário(a) ou secundarista, MC de rap ou funk, jogador de futebol amador, usuário de smartphones, tema das políticas públicas, e, enfim, o citadino que habita e circula pelos diferentes espaços urbanos.

Abrindo o dossiê, temos o artigo "Uma revolução interna em movimento": as ocupações estudantis no Paraná: dos processos formativos às trajetórias pósocupações". Trata-se de uma análise sobre as ocupações estudantis ocorridas no estado do Paraná no ano de 2016. Partindo de entrevistas com jovens que participaram dessas

\footnotetext{
${ }^{7}$ De acordo com o sociólogo José Machado Pais (2003), a corrente geracional toma a noção de juventude como uma fase da vida, destacando o aspecto unitário da juventude, já a corrente classista, percebe a reprodução social da juventude em termos de classes sociais. Desse modo, a transição dos jovens para a vida adulta estaria pautada por desigualdades sociais.
} 
intervenções, Ana Luísa Fayet Sallas, Simone de Fátima Flach, Suely Aparecida Martins e Luis Antônio Groppo se propõem a analisar as experiências vivenciadas pelos agentes na ocasião, buscando pistas para compreender os desdobramentos desses acontecimentos nas trajetórias dos jovens. Além de promoverem uma reflexão sobre uma das mais importantes ocupações realizadas por estudantes no país, os autores discorrem sobre processos formativos responsáveis pela constituição de sujeitos políticos.

Na sequência temos o texto intitulado "O uso do smartphone é um bom começo": estudo das sociabilidades juvenis em contexto pedagógico. Os autores Edgard Leitão e Vanderlan Silva apresentam uma investigação sobre a produção das sociabilidades juvenis em contexto escolar mediadas pelas tecnologias digitais da informação e da comunicação. A reflexão é resultado de uma pesquisa de campo desenvolvida entre os anos de 2018 e 2019 em uma escola pública do ensino médio do estado da Paraíba. Os dados utilizados são frutos de uma intensa observação do cotidiano da sala de aula, bem como de entrevistas com os(as) estudantes.

Juventude, trabalho e lazer no Funk de São Paulo de Marcos Pina, traz uma discussão sobre as relações de trabalho produzidas pelo "mercado do funk" a partir dos anos 2000, quando o gênero musical passa a ser visto como uma possibilidade de inclusão econômica e social para parte dos jovens periféricos. O antropólogo analisa as trajetórias de um MC e um DJ que atuam na Cidade Tirandentes com o intuito de compreender as estratégias mobilizadas pelos artistas visando uma inserção profissional "bem-sucedida". Além de entrevistas com os interlocutores-chave, Pina acompanhou entre os anos de 2019 e 2020 bailes de rua e apresentações em casas de espetáculo.

Leandro Rogério Pinheiro, no artigo, "Рra puxar o jogo..." Jovens e futebol nas periferias de Porto Alegre, traz a experiência de jovens das periferias urbanas de Porto Alegre em um time de futebol que participava de campeonato amador. Dessa maneira, o autor discute como esse circuito do futebol configura um importante espaço de experimentação da condição juvenil. Ainda que essa experimentação implicasse uma disputa constante, dada a precariedade que marca a vida dos interlocutores da pesquisa.

Na sequencia temos o artigo "Juventudes, Coletivos e Políticas Públicas", de Frank Marcon e Leticia Galvão. Trata-se de uma análise das políticas públicas voltadas às juventudes no estado de Sergipe, destacando em que medida estas estão sendo produzidas a partir de demandas advindas de atuação política juvenil, especialmente dos coletivos. Além de apresentar um estado da arte em torno das pesquisas sobre juventude em Sergipe, a dupla analisa alguns dados sobre as políticas direcionadas para os jovens produzidas pelo estado e por alguns municípios, bem como as estratégias mobilizadas pelos coletivos visando a reivindicação de direitos no campo do lazer e da cultura. 
O texto "Caminhadas à universidade: percursos ao ensino superior entre jovens universitários de origens populares no interior cearense", de Ricardo Macêdo e Teresa Queiróz, analisa as trajetórias de estudantes universitários das classes populares mostrando os percursos e "percalços" vivenciados por aqueles e aquelas que decidem fazer um curso de nível superior. Com um olhar atento para as dimensões estruturantes de classe e gênero, o autor e a autora analisam os desafios vivenciados pelos jovens para adentrar e permanecer na universidade, mas sem perder de vista os movimentos de reflexividade e criatividade que tensionam essas determinações sociais.

Em Práticas juvenis e patrimônio: deslocamentos das notas de rodapé de uma pesquisa, Angélica Silvana Pereira explora a relação entre as práticas juvenis e o patrimônio, por meio de uma investigação sobre encontros de jovens que ocorre no Parque da Redenção, em Porto Alegre. Embora a questão do patrimônio não seja uma temática fundamental de reflexão para os jovens que ali se encontram, o próprio parque em si suscita essa questão, pois é considerado um patrimônio da cidade. Estabelecido como ponto de encontro juvenil, esse espaço urbano específico leva a autora a refletir sobre ele com uma zona de contato, que propicia a aproximação de diferenças, mas também a criação de conflitos, que se revelam nas performatividades e sociabilidades juvenis.

Marcos Ferreira, por sua vez, em Viver, morar, trabalhar: práticas sociais e etnicidade entre jovens mayas em Mérida, México, apresenta-nos parte de sua etnografia sobre segregação urbana na cidade de Mérida, no estado mexicano de Yucatán. O autor trabalha a partir das perspectivas dos jovens maya, moradores da periferia da cidade pesquisada. Por meio de um trabalho de levantamento de histórias de vida de alguns jovens, aqui apresentados, Ferreira discute como eles constroem o seu espaço urbano cotidiano, a partir dos diferentes modos como habitam, trabalham e circulam pelo lugar onde vivem.

A questão de como os marcadores de idade, geração, classe social, raça e território interseccionam-se na experiência universitária de jovens estudantes da Universidade de São Paulo é o que orienta o artigo "Não há mais chance de não querer seguir este caminho": grafias de uma geração de jovens na universidade pública. A partir de comunicações pessoais e relatórios escritos dos estudantes em projeto de pesquisa e extensão, do qual é supervisora, Érica Nascimento articula etnograficamente narrativas de estudantes, que, muitas vezes, compõem a primeira geração de suas famílias a acessarem o ensino superior e principalmente uma universidade pública. Dessa maneira, o texto apresenta, ao mesmo tempo, os projetos biográficos dessa juventude e os dilemas vividos atualmente no cotidiano da própria universidade.

A temática da condição de estudante é também trabalhada por Bruno Guilhermano Fernandes, no artigo: Experiências juvenis em espaços urbanos: a influência do espaço escolar. Dessa vez, no entanto, o olhar volta-se para os estudantes secundaristas de uma 
escola pública de Porto Alegre. O autor explora como a experiência de jovens moradores de regiões periféricas da cidade insere-se no cotidiano escolar. Assim, o texto explora as diferentes formas desses jovens habitarem a cidade, por meio de um olhar concomitante para seus trajetos no espaço urbano e suas trajetórias biográficas.

Finalizando o dossiê temos o artigo "Rap indígena como guerra e como cultura: desentendimentos entre jovens e antigos acerca do nãndereko, de Rodrigo Amaro, que versa sobre o impacto da música rap na vida dos jovens que vivem na reserva indígena de Dourados, MS. O antropólogo volta seu olhar para grupos de rap indígena mostrando como estes vêm reconfigurando aspectos da "cultura tradicional" a partir de referências globais como o hip hop, e mais especificamente a música rap. Apoiado em uma vigorosa pesquisa etnográfica, o autor analisa como jovens reelaboram uma importante categoria nativa Kaiowa, aproximando-a de sentidos construídos pela linguagem da cultura hip-hop, o que tem gerado tensionamentos entre os jovens e os antigos membros da comunidade.

O dossiê que aqui organizamos é o resultado de um esforço coletivo para conectar pesquisas sobre juventude de diferentes áreas, mas em especial das Ciências Sociais e da Antropologia, que se inicia a partir de uma rede de pesquisadores, da qual somos membrosfundadores, a REAJ (Rede de Estudos e Pesquisas sobre Ações e Experiências Juvenis), criada em 2017, em Maceió, por ocasião do II SEJUVE (Seminário Juventudes Contemporâneas). Esse evento reuniu cientistas sociais brasileiros que pesquisam o tema da juventude. Nesses quatro anos, desde a sua fundação, a rede ampliou-se e tem incorporado também pesquisadores(as) de fora do campo das Ciências Sociais, como da Educação, da História, da Geografia, entre outras. A REAJ tem produzido uma série de atividades coletivas em torno das múltiplas questões que afetam os jovens brasileiros, como publicações, encontros e eventos. Em 2021, realizou-se o III SEJUVE, com a temática: resistências e recrudescimentos em tempos de crise. Nesse sentido, consideramos que este dossiê é um desdobramento deste esforço coletivo da rede de pautar academicamente a temática da juventude. Neste caso, a partir de um campo muito específico o de uma antropologia da juventude.

\section{REFERÊNCIAS}

ABRAM0, Helena Wendel. Cenas juvenis - Punks e Darks no espetáculo urbano. São Paulo: Editora Scritta, 1994.

BRITTO, Sulamita. Sociologia da Juventude I. Sociologia da Juventude I. Rio de Janeiro: Zahar, 1968.

CAIAFA, Janice. Movimento Punk na Cidade: invasão dos bandos sub. Rio de Janeiro: Jorge Zahar, 1985.

CARDOSO, R.C.L. 0 papel das associações juvenis na aculturação dos japoneses. Revista de Antropologia, v. 7, n. 1, p. 101-122, 1959. 
CLASTRES, Pierre. A sociedade contra o Estado. São Paulo: Cosac Naify, 2003 [1974].

COSTA, Márcia Regina da. Os carecas do subúrbio - caminhos de um nomadismo moderno. Petrópolis, RJ: Vozes, 1993.

DIÓGENES, Glória. Cartografias da Cultura e da Violência. São Paulo: Annablume, 1998.

FIRTH, Raymond. Nós, os Tikopias: um estudo sociológico do parentesco na Polinésia primitiva. São Paulo: Edusp, 1998 [1936].

FORACCHI, Marialice. 0 estudante e a transformação da sociedade brasileira. São Paulo: Companhia Editora Nacional, 1965.

A juventude na sociedade moderna. São Paulo: Pioneira, 1972.

KEMP, Kênia. Grupos de Estilo Jovens: 0 "Rock Underground" e as práticas (contra) culturais dos grupos "punks" e "trashs" em São Paulo. 1993. Dissertação (Mestrado em Antropologia) - Programa de Pós-Graduação em Antropologia, Universidade Estadual de Campinas, Campinas, 1993.

LATOUR, Bruno. Jamais fomos modernos: ensaio de antropologia simétrica. São Paulo: Editora 34, 1994.

MEAD, Margareth. Coming of age in Samoa: a psychological study of primitive youth for western civilization. New York: Mentor, 1949.

PAIS, José Machado. Culturas Juvenis. Lisboa: Imprensa Nacional-Casa da Moeda, 2003.

POERNER, A. J. 0 Poder Jovem - história da participação política dos estudantes brasileiros. $2^{\text {a }}$ ed. Rio de Janeiro: Civilização Brasileira, 1979.

TURNER, Victor. 0 processo ritual: estrutura e anti-estrutura. Petrópolis, RJ: Vozes, 1974.

VAN GENNEP, Arnold. Os ritos de passagem. Petrópolis: Vozes, 2011 [1977].

VIANA, Hermano. Mundo funk carioca. Rio de Janeiro: Jorge Zahar, 1988. 